\title{
MISCELLANEA
}

\section{Some Personal Observations on Industrial Health in the United States of America BRYAN HARVEY*}

Any account of industrial health in the U.S.A. should start with Dr. Alice Hamilton. $\dagger$ The autobiography of this remarkable woman records not only the author's life-long devotion to the cause of the American industrial worker, but gives a picture of conditions in American industry which, when she first began her work, were a veritable jungle of ignorance, prejudice, and suspicion. But if Dr. Hamilton showed the way out of these unpromising conditions, it was perhaps the alteration in American compensation law which provided the driving force toward change.

Industrial health may have owed something in its early stages to the experience of other lands, but the pattern which has so recently emerged is wholly American. Receiving little but advice from the Federal Government it takes its inspiration from the State compensation laws. Since these vary from State to State so also does the provision for industrial health. Most States in addition enforce, through their health departments, minimum standards ; but these also vary.

Most characteristic is the stimulus which compensation law gave to private enterprise. The insurance companies carrying the new burdens of compensation for industrial disease enrolled the services of the engineer and the chemist to control the health hazards of industry. So too did individual firms. That these firms saw the new services as extensions of their plant maintenance departments rather than of their medical departments seems to have had profound effects on subsequent development. This outlook introduced industrial hygiene as a new profession and has resulted in a characteristically American approach to the problems of industrial health, not the least feature of which was at the beginning the separation of industrial hygiene and industrial medicine.

\section{Industrial Hygiene}

While industrial hygiene in its widest sense is common to all countries with an industrial civilization, in its

* Mr. Harvey, one of H.M. Inspectors of Factories in the British Factory Department, was awarded a Rockefeller Foundation Fellowship for graduate studies in the Harvard School of Public Health in order to study industrial health in the U.S.A., and this article represents order to study industrial health in the impressions gained in the course of his American visit. Any views expressed are personal to Mr. Harvey and do not necessar

$\dagger$ Hamilton, Alice, (1943). Exploring the Dangerous Trades. Little, Brown and Co., Boston. narrow sense it is par excellence the American contribution to industrial health. In so far as it is definable at all it comprises the measurement and control of industrial toxic hazards - that measurement being mainly of atmospheric contaminants while control is largely the engineering control of airborne poisons. This is not, however, an exclusive definition since other conditions, for instance, lighting and noise, to an increasing extent fall within the range of industrial hygiene.

The industrial hygienist is therefore part chemist, part engineer, and part toxicologist, though of course the clinical field is closed to him. Even so it seems that the American medical profession is less exclusive on these issues than its British counterparts and more ready to accept as colleagues workers trained in other sciences.

There is a good deal of concentration on methods of air analysis in order to determine the amount of contaminants in the atmosphere. This side of the industrial hygienist's work is highly developed, and involves serious academic training. Hygienists are employed by Federal and State agencies as well as by insurance companies and private firms.

Most of the techniques are well known in this country ; their novelty lies chiefly in their widespread use, and their acceptance often without qualification as a measure of industrial conditions. Grab sampling into exhausted bottles or by means of aspirators, and integrated sampling over a period of time are widely used, and the necessary laboratory equipment and facilities for analysis are provided as a matter of course. The use of physical methods as opposed to chemical methods is also being developed, and research into this rather specialized field of instrumentation is actively pursued. As yet these methods are not widespread.

The development of regular air sampling and analysis has resulted in the determination of theoretically allowable maximum concentrations. The present list sponsored by the Conference of Governmental Industrial Hygienists was started in about 1940 and is now almost universally accepted. It is from time to time amended, almost always by reducing the allowable concentration formerly accepted as safe, and this in itself is a powerful argument for those who object to the system. The argument put forward in justification is that if contaminants are to be controlled mechanically there must be a standard of atmospheric cleanliness to work to, a tacit rejection of $100 \%$ purity. These arguments do not always find favour in English eyes though they would seem to derive considerable support from pure logic.

Some at least of this technique of air analysis has been forced upon the hygienist since in the United States there is nothing comparable to Section 47 of the British Factories Act, which allows the word 
"offensive" to be an acceptable reason for providing exhaust ventilation. In almost every case where supposed toxic risks are encountered investigators have to show either physically or chemically that the agent is present in the atmosphere being breathed by the workers and that it is toxic. While this to some extent is a limiting factor, it can also demonstrate on occasion the presence of toxic materials in the atmosphere which were hitherto unsuspected.

Accurate assessment of air contaminants, particularly where the presence of small concentrations of some of the newer industrial poisons can be demonstrated, does notably assist in controlling health hazards. The American experience with metallic poisons such as beryllium, which has not so far been matched in this country, is a good example of the advantages of developing accurate air sampling techniques.

Some of the standards of dust sampling and counting which are considered acceptable are by our methods unsatisfactory since the official ideas on dust concentrations in the United States are based upon sampling by means of the Greenburg-Smith impinger which, so far as recent investigations show, may allow much of the dust of respirable size to escape. While a variety of methods of counting dust so collected has been developed, many workers, including the U.S. Public Health Service, feel that the whole technique is unsatisfactory. One of the difficulties, however, in getting rid of it lies in its widespread acceptance and in the fact that concentrations of dust based upon these methods have been accepted throughout the country as standards. This is a further example of the shortcomings of officially accepted lists of maximum allowable concentrations, particularly if the methods of determining the concentrations are not above reproach.

Other methods of sampling are, however, used in the United States, though the thermal precipitator does not appear to gain much favour, chiefly, I believe, because of the time needed for sampling.

One interesting instrument, developed by Bausch and Lomb, is effectively an improved version of the Owens jet dust counter. It consists of a pump of known capacity, a series of 14 microscopic slides which can be rotated on a disc, and a dark field microscope complete with its own lighting unit. It will take 14 separate dust samples and the graticule within the microscope allows the samples to be counted accurately in a short space of time. The results may not be quite so good as those achieved with the thermal precipitator but by virtue of the dark field method small particles can be counted, and the method is so simple that any normal person should with a little training be able to take and count dust samples with acceptable accuracy.

The very nature of this approach, involving, as it does, considerable theoretical training in the techniques of air sampling, has led to a noticeable concentration on theory. This is not, probably, a monopoly of industrial hygiene. In all aspects of life in America a high place is accorded to the scientist, and the theoretical approach has great popular appeal which is stimulated by advertisements. The theoretical approach has many advantages but is not without defects, the chief being that it tends to discount the common sense solution to any problem solely because it is simple. It may even lead to the elaboration of common sense solutions in order to make them acceptable.

Some of this has been forced on the industrial hygienist by conditions in industry itself. There is a strong feeling against any action to improve conditions until the industrial hygienist can demonstrate by instruments the presence of poison in the atmosphere. This attitude has led to the development of more and more accurate and involved means of air analysis in an effort to be more convincing to management. There may be a tendency, as a result, to judge the worth of the industrial hygienist by his skill in handling instruments rather than by his broad appreciation of the dangers of industry. Air analysis itself, unsupported by general background knowledge, may well have special pitfalls, particularly if the safe limits for an atmospheric contaminant are small. Sometimes the amounts to be measured are minute in the extreme, and the difference between safety and danger may be outside the margin of error inherent in the method of analysis. At the other extreme demands for scientific proof may lead occasionally to the curious spectacle of an industrial hygienist taking air samples in a room impossible to see across because of the density of the dust cloud. Industrial hygienists do not enjoy this sort of thing but are forced into it to show measurable proof of their observations. As a whole, American industry has more appreciation for the hygienist who can say, for example, with real accuracy how much benzene there is in the air than for the man who declares that the best way to end benzene poisoning is to get rid of benzene.

It is particularly noticeable, both in the academic field and elsewhere that among the lines of defence proposed against industrial poisons, substitution was the last, whereas in this country it is the first. All concerned with this work are heavily indoctrinated with the view that the industrial hygienist should confine himself to industrial hygiene and not propose changes in the productive process itself. It is almost an admission of failure by the industrial hygienist if he is forced to seek a substitute for the dangerous material. In this respect American thinking is fundamentally opposed to British thinking and strangely at variance with its own views on industrial safety, where it is held that safety is a problem of production and can only be solved by means of the normal administrative machinery of production.

It would be a mistake because some features of the American picture are unusual to British eyes to discount the tremendous work which is being done to improve industrial conditions. When one measures the progress made in so few years the results are really startling. Much of this credit must go to the insurance companies which quickly taught industry that industrial hygiene would pay. But much also belongs to private industry with its capacity for rapid change. One result of the compensation laws has been to introduce 
this new fully accepted profession to American life with adequate financial support and its own facilities for teaching and research. There is now a vast and ever growing body of theoretical and practical knowledge of industrial hygiene in a climate of sympathetic public opinion which accepts the control of industrial health hazards as a separate branch of the science of public health. Whatever its deficiencies may be it can hardly fail to make progress. Americans are conscious of many of the defects themselves. In particular the recent trouble experienced with beryllium has given rise to fears that American industry by its very nature can produce new hazards faster than industrial hygiene can provide protection for them. Beryllium poisoning was a disaster because it eluded all their efforts and they feel that the same thing can happen again. In fact, there is now apprehension about the increasing use of radioactive isotopes. Already a number of minor incidents involving their unauthorized removal by employees and the distribution of components containing radioactive material from one company to another without any warning of the dangers have occurred. The use of these materials grows every day, and while at the moment the public is aware of the dangers (some might say over aware), this is bound eventually to be offset by familiarity as the years go by. Even now there have been enough incidents to cause considerable anxiety.

In atmospheric control the theoretical approach in industrial hygiene has paid handsome dividends. Interesting developments both in the control of purely toxic hazards by exhaust ventilation and also in the wider field of general ventilation are evident.

Air conditioning, often originally installed in industrial undertakings for the sake of the product, is now being considered also for its effect on the comfort of the operative and his consequent improved output. It involves the complete control of temperature and humidity, including refrigeration, and is a development peculiarly American in its origin. In the United States it is only the far western seaboard which enjoys a temperate climate. The rest of the country is beset with extremes of temperature at either end of the scale and generally at both. It is an interesting speculation as to what effect this control of natural environment will have on Americans themselves. For it is becoming widespread to the extent that one can buy an air-conditioning unit for the living-room or bedroom from the corner drug store ; and air conditioning of large public buildings and offices is becoming universal.

The possibility of boosting output by improved physical conditions has not escaped the notice of American industry, and while air conditioning solely for this purpose is not common, one or two interesting developments were noted. For example, the air conditioning of a roller man's " pulpit" in a large steel works proved well worth while in relation to the importance of the work which the man was performing.

In the whole field of ventilation, and in particular in the design of exhaust plants, there is evidence of wide appreciation of the theoretical problems of design, and great skill and ingenuity are used to overcome them. In this respect the universities deserve praise for turning out graduate hygienists with a good theoretical background. Ventilation problems appear to be tackled with greater skill and knowledge than in this country. A particularly ingenious example of this was in the fresh air supply provided for a crane cab in a steel works where there was danger of carbon monoxide poisoning. In the same works polished aluminium sheets had been used with great success to keep out radiant heat in various parts of the works-including the bottom of all the crane cabs near furnaces.

Application of modern dust control by ventilation in foundries is also good, and here again examples of ingenuity backed by good theory were apparent in adapting the ventilation plant to the processes. Where industrial hygiene was taken seriously, quite remarkably high standards of atmospheric control were often achieved and in this respect we in this country have something to learn.

The hygienist is now developing interest in problems related to the comfort of the worker. This development has recently received a remarkable stimulus from the Compensation Acts in relation to noise. Several successful claims for loss of hearing due to occupation have been made leading to much investigation by insurance companies and Federal authorities. In particular it is thought desirable to find if a " maximum allowable concentration" of noise can be determined which will not result in loss of hearing. The Federal Public Health Service is engaged in a long-term investigation undertaken in the Federal prisons among other places. The problem of loss of hearing already sustained before employment is also of great interest to insurance companies since some have already had to pay compensation for industrial injuries to former naval gunners. The tightening up of pre-employment examinations to include an audiogram is one result.

The social and economic climate in the U.S.A. is particularly favourable to research both because the capital resources are readily available, and also because scientific research is considered almost as part of the American way of life. It is possible to be over critical and say that some money is spent on projects which hardly merit it, but this may well be a small price to pay for the valuable information which is being gathered over the years in a comparatively new subject. Studies are going on in widely diverse fields. They range from the estimation of the effects of the absorption of minimal quantities of lead over long periods to investigations of the hazards of the industrially important rarer metals and of the cause of industrial cancer. The last two projects are under the aegis of the United States Public Health Service.

The Atomic Energy Commission sponsors both physiological research into the effects of radiation and also research into the problems of ventilation and air cleaning. Despite the problems of security the results seem to have been made readily available. Especially interesting in this connexion is some work done in Massachusetts in the so-called "chelating" agents. Ethy- 
lene diamene tetra acetic acid ("versene") has been shown to stimulate to a marked degree the excretion of lead in those suffering from lead poisoning, and it is felt that it may also have a practical application to radioactive materials. Some work on this has been done in this country also. Some doubts have been expressed, however, that this particular drug may stimulate the excretion of essential trace elements, a development which might prove difficult to control.

Industrial hygiene is essentially an American approach, and it enjoys the virtues and defects of other American institutions. It shows great energy and drive and the marked characteristics of the vigorous private enterprise that so largely supports it. It lacks, to English eyes at least, coordination. What State control there is, is of 48 different varieties. Americans fight shy of the regular coordinated State inspection of industry so well established in Europe, and in consequence they lack some of the advantages of that system. In particular they lack national accurate statistics of the incidence and morbidity of industrial disease. While one may well be lost in admiration for the forceful and painstaking efforts which industrial hygiene is making to control the industrial environment there is little accurate data by which to judge its success.

While compensation insurance, the backbone of the American system, has done so much to stimulate the control of known occupational hazards, it may not to the same extent encourage either the medical profession or the industrial hygienists to discover new industrial diseases and hazards. British industry as a whole has come to accept perhaps more readily the implications of research into industrial disease and does not now to any marked degree contest their results. American industry in insisting on scientific proof of toxic dangers and their presence in the atmosphere seems to delay to some extent the application of measures of control, and this may account for some occupational diseases being undiagnosed in the United States while in this country they are accepted without controversy.

\section{Industrial Medicine}

An older development than hygiene, industrial medicine in the United States, though now largely a growth of the Workmens Compensation Act was originally based upon the first-aid department, or the "plant hospital" in the larger factories. The earliest industrial medical officers were drawn from the ranks of the surgeons, and dealt largely with physical trauma. Industrial medicine has, however, taken on new functions and is now considered for recognition as a specialty.

While the American industrial medical officer of today is very different from his predecessor, he is by no means always an industrial toxicologist, for the problems of industrial toxicology are left largely to the industrial hygienist. Indeed several large plants have medical departments and also industrial hygiene departments, in many cases wholly separate from each other.

Industrial medicine is conceived largely in the United States as clinical medicine applied to the factory as a group rather than to the individual as in private practice.
It is preventive in its emphasis on keeping people well rather than in curing disease. The purpose of the medical department is to keep people at work and to keep them efficient while they are at work. This has led to a development which is of considerable importance, namely, the pre-employment medical examination. In some firms there are also periodical examinations which may extend from the office boy to the president of the company. A variety of forces have been responsible for this development, the first and obvious one being to make sure that the company does not employ any person who is physically incapable of doing the work assigned to him. This goes hand in hand with the American emphasis upon fitting the worker to the job and in finding out both his physical and psychological capabilities. This desire not to employ people who are physically unfit for particular work has by pressure of events and particularly by pressure of compensation law widened the scope of these examinations to exclude a variety of people who may well be "bad risks". Since in most States where compensation laws are in force compensation is payable for aggravation of an existing condition, and since aggravation is interpreted both by the compensation tribunals and also by the courts in an ever wider sense, the pre-employment medical examination tends to become ever more strict. A striking recent example has already been mentioned, namely, that since insurance companies are now being forced to pay compensation for loss of hearing in noisy occupations, it has become important to determine the hearing ability before employment.

Periodical medical examinations are also a means of assessing damage to the individual from his occupation, and in this respect are an important check on the work of the industrial hygienist in controlling the hazards of an industry. They may, however, be used as a substitute for controlling the hazards by enabling the industry to remove employees from dangerous environments before they develop symptoms which are compensatable. While this view may not be widespread it certainly exists.

Pre-employment medical examinations in conjunction with aptitude testing have become standard procedure in most large American works, and though they have run into some difficulties with trades unions, the system has so far never been applied extensively except in periods of full employment. The main object of the medical department in its physical examinations, both the pre-employment and also, where practised, the periodical, is to prevent employment of the physically handicapped in occupations which may aggravate their condition. It is, however, no great advance to use this technique to prevent the employment of the physically handicapped at all. In time of serious unemployment the pre-employment physical examination might be used as a weapon to prevent all but the most healthy individuals obtaining work. Already in those factories where periodical medical examinations are undertaken, problems have arisen in connexion with the ageing employee who is declared by the medical 
department to be physically unfit for the job that he is now performing and is forced to accept some other job. Even if this does not involve lowering of pay, it may involve loss of seniority which where " first in, last out" rules are applied, is a source of considerable bitterness.

The treatment of injury is, of course, always a problem and most large plants have well set up and lavishly equipped medical departments which sometimes include a small operating theatre. Most space is generally given, however, to examination rooms due perhaps to the higher labour turnover of American industry. While industrial medical officers are now trained in industrial toxicology and may well have considerable knowledge of toxic risks, one does not gain the impression that this side of industrial medicine takes a very prominent place in their outlook or activity.

A remarkable reduction in lost time from accidents has been noticed in factories where a medical department has been set up. The exact relationship between the work of a medical department and these reductions is not known, but it must be connected to some degree with improved treatment of injury so that infection rarely occurs and with getting injured persons back to work more quickly. In this respect a well-run department may induce a man to stay at work though injured, since he can get regular medical attention within the works itself, whereas if he is taken off to an outside doctor or to the casualty department of a hospital he is normally sent home and not back to work. In fact it is a policy of a plant medical department to prevent minor injuries becoming major injuries. The great attention given by American industry to preventing workers staying away from work because of accidents and to get them back when they have stayed away, is of considerable interest, for there can be little doubt that the rehabilitative effects of work, even of the lightest character, are greater than the best influence that can be brought to bear in the home. And in this the medical departments of American industry are doing very important work.

\section{Conclusion}

It is foolish for anyone to imagine that he can assess the institutions or the way of life of another country wholly objectively, for however hard we try our reactions are conditioned to some extent by the opinions and, above all, the prejudices which we bring from our own land. This is particularly true of the Americans and the British, for so often our similarities in outlook and in language serve to conceal the very marked differences between the two countries ; we are, as Bernard Shaw said, " two nations divided by a common language."

There is, however, one marked impression left in the mind when considering industrial health in the United States. It is the lack of coordination of the efforts of the various persons interested in the subject. To say this is not to be unaware of the national background provided by American history that probably makes this inevitable. America has no industrial enforcement service such as the Factory Department in this country to establish the minimum standards of industrial health without fear or favour and without reference to geographical barriers. More important, as a result, she has no statistics of industrial disease for the nation as a whole. It is this more than anything which makes it difficult to assess the success of American enterprise in this realm.

\section{THE APRIL (1954) ISSUE}

The April (1954) issue contains the following papers :-

Tumours of the Urinary Bladder in Workmen Engaged in the Manufacture and Use of Certain Dyestuff Intermediates in the British Chemical Industry. Part I. The Role of Aniline, Benzidine, Alpha-Naphthylamine, and BetaNaphthylamine. By R. A. M. Case, Marjorie E. Hosker, Drever B. McDonald, and Joan T. Pearson.

Tumours of the Urinary Bladder in Dogs after Ingestion of 4-Aminodiphenyl. By A. L. Walpole, M. H. C. Williams, and D. C. Roberts.

An Industrial Health Service in Norway. By Haakon Natvig.

Fatal Emphysema in Two Men Making a Copper Cadmium Alloy. By Ronald E. Lane and A. C. P. Campbell.

A Study of Boils at Three Collieries. By O. P. Edmonds, R. H. P. Fernandez, and L. B. Bates.

Individual Differences in Accident Susceptibility Among Coal Miners. By J. W. Whitfield.

The Toxicity of Nitrogen Pentoxide. By W. M. Diggle and J. C. Gage.

The Development of Lymph Nodes after Injection of Flint of Variable Size into the Lungs of Rats. By G. Nagelschmidt, E. S. Nelson, E. J. King, and C. V. Harrison.

The Effect of Oiling the Cotton on the Airborne Contamination in Card Rooms. By D. G. Drummond, Mary Hamlin, J. K. Donoghue, and F. Brownsett.

Miscellanea :

A Simple Micromethod for the Determination of Lead in Small Amounts of Blood. By P. E. Cornish and D. O. Shiels.

Three Approaches to the Study of Personality. By Alastair Heron.

A number of copies are still available and may be obtained from the Publishing Manager, British Medical Association, Tavistock Square, W.C.1, price 12s. 6d. 